\title{
VALIDATED FIRST-ORDER DERIVATIVE SPECTROPHOTOMETRY FOR SIMULTANEOUS DETERMINATION OF EMTRICITABINE AND TENOFOVIR DISOPROXIL FUMARATE IN PHARMACEUTICAL DOSAGE FORM
}

\author{
*Sunitha. P. G ${ }^{1}$, Kaliappan.Ilango², \\ ${ }^{1}$ Department of Pharmaceutical Chemistry,College of Pharmacy, Madras Medical College, Chennai-600 003 \\ ${ }^{2}$ Department of Pharmaceutical Chemistry, SRM College of Pharmacy, SRM University, Kattankulathur-603 203 \\ *Corresponding Author's E-mail: sunitha.srm@gmail.com
}

\begin{abstract}
A simple, precise, accurate, and economical spectrophotometric method has been developed for simultaneous estimation of emtricitabine(EMB) and tenofovir(TEN) by employing first-order derivative spectrophotometric method. The first derivative spectrum is a plot of the rate of change of absorbance with wavelength against wavelength $(\mathrm{dA} / \mathrm{d} \lambda$ versus $\lambda$ ). It is characterized by a maximum, minimum and a cross- over point at the $\lambda \max$ of the absorption band. The linearity was established over the concentration range of $6-16 \mu \mathrm{g} / \mathrm{mL}$ and $9-24 \mu \mathrm{g} / \mathrm{mL}$ for EMB and TEN with correlation coefficients 0.9994and 0.9992, respectively. The mean percentage recoveries were found to be $99.99 \%$ for EMB and $100.43 \%$ for TEN. The proposed method has been validated as per ICH guidelines and successfully applied for the simultaneous estimation of EMB and TEN in combined tablet dosage form.
\end{abstract}

Keywords: emtricitabine, tenofovir, spectrophotometry

\section{INTRODUCTION:}

Emtricitabine and Tenofovir are antiretroviral drugs used for the treatment of $\mathrm{HIV}^{1}$. Forstavir - EM is the combination of the two drugs containing $200 \mathrm{mg}$ of EMB and $300 \mathrm{mg}$ of TEN. Emtricitabine is chemically 4Amino-5-fluoro-1-[2-(hydroxymethyl)-1, 3-oxathiolan5-yl]-pyrimidin-2-one ${ }^{2,3}$.It is a nucleoside reverse transcriptase inhibitor. The structure of EMB is given in Figure 1.

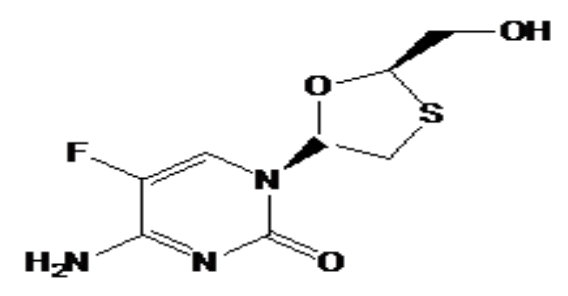

Figure 1: Chemical structure of EMB

Chemically Tenofovir is 1-(6-Aminopurin-9-yl)-prapan2-yl-oxymethylphosphonic acid ${ }^{4}$. It is a nucleotide analogue reverse transcriptase inhibitor. The structure of TEN is given in Figure 2.

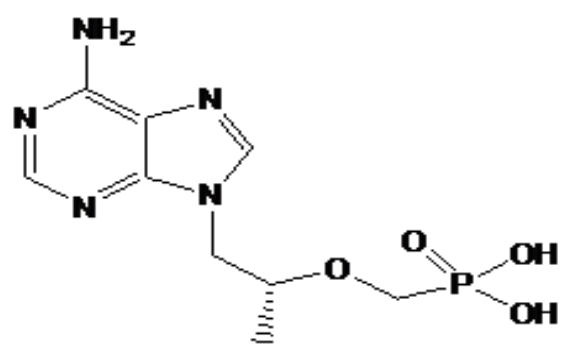

Figure 2: Chemical structure of TEN c) 2011, JDDT. All Rights Reserved
Extensive literature survey revealed that only LCMS/MS ${ }^{5}$ and RP-HPLC ${ }^{6}$ methods for the determination of EMB and TEN in human plasma, RP-HPLC ${ }^{7}$ for determination of TEN in plasma, LC/MS/MS for determination of plasma TEN concentrations ${ }^{8}$, LC-MS method for determination of plasma TEN concentrations ${ }^{9}$ and HPLC with fluorimetric detection for determination of EMB in human plasma $^{10}$ have been reported so far.However, to the best of our knowledge, no first derivative spectrophotometric method is published for the simultaneous determination of EMB and TEN in tablet dosage form. The present work describes the development of a simple, precise, accurate, and reproducible spectrophotometric method for the simultaneous estimation of EMB and TEN in combined dosage form. The developed method was validated in accordance with ICH guideline and successfully employed for the assay of EMB and TEN in combined tablet dosage form.

\section{MATERIALS AND METHODS:}

\section{Chemicals and Reagents}

Working standards of EMB and TEN were provided as gift samples by Ranbaxy Laboratories, India. Forstavir EM tablets were purchased from a local pharmacy.

\section{Instruments}

Shimadzu UV-Vis Spectrophotometer-1650, $1 \mathrm{~cm}$ matched quartz cells, and UV probe 2.34 software was used. Calibrated analytical balance Shimadzu BP211D (Sartorius Gottingen AG, Germany) was used for weighing purpose. All statistical calculations were carried out using Microsoft Excel 2007 analytical tool. 


\section{Preparation of Standard Stock Solutions}

Accurately weighed $25 \mathrm{mg}$ of EMB and TEN standards was transferred to a separate $25 \mathrm{~mL}$ volumetric flask and dissolved in $10 \mathrm{~mL}$ distilled water. The flasks were shaken and volume was made up to the mark with distilled water. These solutions are $1000 \mu \mathrm{g} / \mathrm{mL}$ EMB and $1000 \mu \mathrm{g} / \mathrm{mL}$ TEN respectively.

\section{Selection of Analytical Wavelength}

Working standard solutions of $6-16 \mu \mathrm{g} / \mathrm{mL}$ of EMB and $9-24 \mu \mathrm{g} / \mathrm{mL}$ of TEN were prepared in distilled water by appropriate dilution, and the spectrum was recorded between 200 and $400 \mathrm{~nm}$, and all zero-order spectrums $\left(D^{0}\right)$ were converted to first derivative spectrums $\left(D^{1}\right)$. The overlain first derivative spectrums of LCT and PHE at different concentrations were recorded.

\section{Method Validation ${ }^{11}$}

The proposed method was validated in terms of linearity, accuracy, precision, limits of detection (LOD) and quantification (LOQ) and reproducibility.

\section{Linearity}

Appropriate aiquots from EMB and TEN standard stock solution were transferred to volumetric flasks of $10 \mathrm{~mL}$ capacity. The volume was adjusted to the mark with distilled water to give working standard solutions containing $6-16 \mu \mathrm{g} / \mathrm{mL}$ for $\mathrm{EMB}$ and $9-24 \mu \mathrm{g} / \mathrm{mL}$ for TEN respectively. All $\mathrm{D}^{1}$ spectra were recorded using the above spectrophotometric condition. $\mathrm{D}^{1}$ absorbance at $257 \mathrm{~nm}$ and $282 \mathrm{~nm}$ was recorded for EMB and TEN, respectively. Calibration curves were constructed by plotting average absorbance versus concentrations for both drugs. Straight line equations were obtained from these calibration curves.

\section{Accuracy}

Accuracy was assessed by the determination of the recovery of the method by addition of standard drug to the prequantified sample preparation. Each concentration was analyzed 3 times, and average recoveries were measured.

\section{Precision}

The repeatability was evaluated by assaying 6 times the sample solution prepared for assay determination. The results are reported in terms of \% RSD.

\section{Detection Limit and Quantitation Limit}

In the present study, the LOD and LOQ were calculated by the use of standard deviation of the response and the slope of the calibration curve.

\section{Reproducibility}

The absorbance readings were measured in a different laboratory, using another spectrophotometer by another analyst, and the values obtained were evaluated to verify their reproducibility.

\section{Determination of EMB and TEN in Their Combined Tablet Dosage Form}

Twenty tablets were weighed and crushed to a fine powder. An accurately weighed powder equivalent to $300 \mathrm{mg}$ of TEN and $200 \mathrm{mg}$ of EMB was transferred to a $100 \mathrm{~mL}$ volumetric flask and dissolved in about $75 \mathrm{~mL}$ of methanol. The volume was then made upto the mark with methanol. The solution was sonicated for about 15 minutes and filtered through Whatmann filter paper $(0.45 \mu)$ and diluted to prepare the concentration of $9-24 \mu \mathrm{g} / \mathrm{mL}$ TEN and $6-16 \mu \mathrm{g} / \mathrm{mL}$ of EMB. The resulting solution was analyzed by the proposed method. The quantitation was carried out by keeping these values to the straight line equation of the calibration curve.

\section{RESULTS AND DISCUSSION:}

First-order derivative spectrophotometric method was developed for determination of EMB and TEN. Figure 3 shows overlain $D^{1}$ spectra of EMB and TEN at different concentrations.

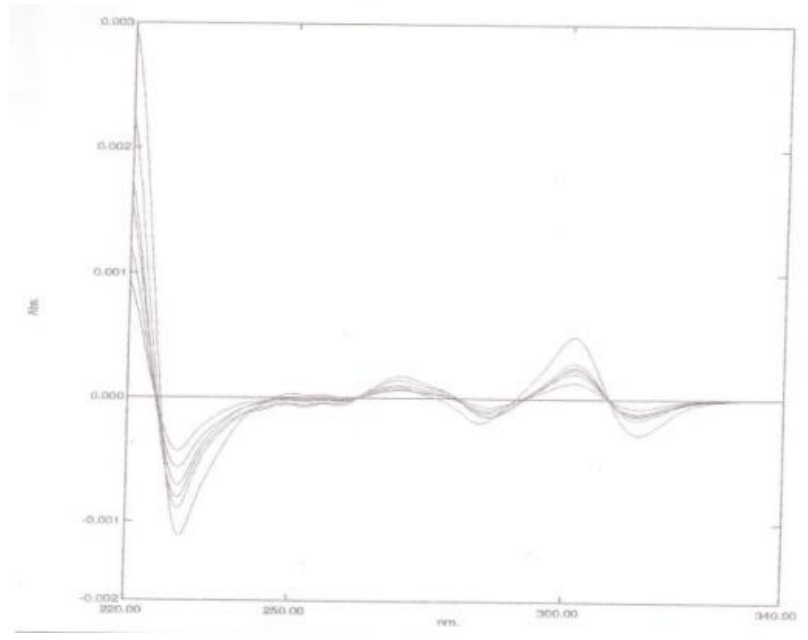

Figure 3: Overlain $D^{1}$ spectra of EMB and TEN

The optical characteristics such as absorption maxima, Beer's law limits and the regression characteristics like slope(b), intercept(c), correlation co-efficient(r), percent relative standard deviation(\% RSD) and standard error(SE) were calculated and the results are summarized in Table-1. The results of sample analysis showed that the drug determined by the proposed methods was in good agreement with the label claim proving the accuracy of the proposed methods.

To study the accuracy and reproducibility of the proposed methods, recovery experiments were carried out by adding a known amount of drug to preanalysed sample and the percentage recovery was calculated. The results are furnished in Table-2. The results indicate that there is no interference of other ingredients present in the formulations. Thus, the proposed method is simple, sensitive, economical, accurate and reproducible and useful for the simultaneous estimation of EMB and TEN in combined tablet dosage form. 
Table 1: Optical and Statistical parameters

\begin{tabular}{|c|c|c|}
\hline Parameters & EMB & TEN \\
\hline $\begin{array}{c}\text { Absorption maximum/ } \\
\text { Wavelength range }(\mathrm{nm})\end{array}$ & $200-400$ & $200-400$ \\
\hline Linearity Range $(\mu \mathrm{g} / \mathrm{mL})$ & $6-16$ & $9-24$ \\
\hline Correlation coefficient & 0.9994 & 0.9992 \\
\hline$\%$ RSD & 0.0460 & 0.0307 \\
\hline Standard Error(SE) & 0.0424 & 0.0122 \\
\hline Regression Equation & $0.9089 \mathrm{x}+0$ & $0.5065 \mathrm{x}+0.1$ \\
$\mathrm{y}=\mathrm{mx}+\mathrm{c}$ & .1414 & 223 \\
\hline Intercept $(\mathrm{c})$ & 0.1414 & 0.1223 \\
\hline Slope $(\mathrm{m})$ & 0.9089 & 0.5065 \\
\hline LOD $(\mu \mathrm{g} / \mathrm{mL})$ & 0.1180 & 0.1212 \\
\hline $\mathrm{LOQ}(\mu \mathrm{g} / \mathrm{mL})$ & 0.3601 & 0.3672 \\
\hline
\end{tabular}

Table 2: Assay and recovery of EMB and TEN

\begin{tabular}{|c|c|c|c|}
\hline Method & Labelled amount $(\mathrm{mg})$ & Amount obtained $(\mathrm{mg}) *$ & Percentage recovery** \\
\hline EMB & 200 & 199.75 & $99.99 \%$ \\
\hline TEN & 300 & 299.45 & $100.43 \%$ \\
\hline \multicolumn{2}{|c}{} \\
\hline
\end{tabular}

\section{CONCLUSIONS:}

The proposed first-order derivative method provides simple, specific, precise, and accurate quantitative analysis for simultaneous determination of EMB and TEN in combined tablet dosage form. The method was validated as per ICH guidelines in terms of linearity, accuracy, precision, limits of detection (LOD) and

\section{REFERENCES:}

1. Martindale. The Complete Drug Reference, $35^{\text {th }}$ Edition, 2007, Pharmaceutical Press London, 811.

2. Indian Pharmacopoeia 2010. Volume II. Government of India, Ministry of Health and Family Welfare. The Indian Pharmacopoeia Commission.Ghaziabad: 1272-1273.

3. The Merck Index. An Encyclopedia of Chemicals, Drugs and Biological, $13^{\text {th }}$ Edition. Merck Research Laboratories: 630, 1631-1632.

4. Indian Pharmacopoeia 2010.Volume III. Government of India, Ministry of Health and Family Welfare.The Indian Pharmacopoeia Commission. Ghaziabad: 2188-2193.

5. Gomes N.A, Vaidya V.V, Pudage A, Joshi S.S \&Parakh S.A. 2008. J. Pharm. Biomed. Anal, 48(3): 918-926. quantification (LOQ) and reproducibility. The proposed method can be used for routine analysis of EMB and TEN in combined dosage form.

\section{ACKNOWLEDGEMENTS:}

The authors are thankful to Ranbaxy laboratories, India for providing gift samples of both drugs.

6. Baietto L, D'Avolio A, Sciandra M \&Siccardi M. 2008. J. Chromatogr. Sci 46 (6): 524-528

7. Sentenac S, Fernandez C, Thrillers A, Lachat P \&Aymard G. 2003. J. Chromatogr. B, 793(2): 317-324.

8. Delahunty Tom, Bushman Lane, et.al.2006. J. Chromatogr. B830 : 6-12

9. Takahashi Masaaki, Kudaka Yuichi et.al.2007. Biol. Pharm. Bul30 : 1784-1786.

10. Droste A. H, Aarnoutse R. E et.al. 2007. J. Liq. Chromatogr. Rel. Tech 30: $2769-2778$.

11. ICH Harmonized Tripartite Guidelines, Validation of Analytical Procedures: Text and Methodology, Q2(R1), Geneva, Switzerland, 2005. 